\title{
PROYECTO DE ORGANIZACIÓN Y FINES DEL MUSEO DE ARQUEOLOGÍA Y ETNOLOGÍA DE LA UNIVERSIDAD NACIONAL MAYOR DE SAN MARCOS
}

\section{Organización y Fines:}

El Museo de Arqueología y Etnología es un órgano de la Dirección Universitaria de Proyección Social. Por desarrollar actividades de investigación está ligado a la Dirección Universitaria de Investigaciones y, a través de sus servicios para la docencia, al Departamento de Ciencias Histórico-Sociales (Sección de Arqueología) de la Universidad Nacional Mayor de San Marcos.

Su estructura económica y administrativa depende del presupuesto y organización de la Dirección Universitaria de Proyección Social; el funcionamiento de los proyectos de investigación, si bien se integra al funcionamiento global del Museo, depende de las disposiciones emanadas de la Dirección Universitaria correspondiente.

Las relaciones con el Departamento de Ciencias Histórico-Sociales (Sección Arqueología) y con otros Departamentos (Ciencias Biológicas, Humanidades-Arte, etc.), están sujetas al pedido que hagan los Jefes de Departamento ante la Dirección Universitaria, a fin de usar de los servicios del Museo para fines de docencia o investigación (local, laboratorios, personal, información, etc.).

El Museo podrá ligarse también, previa formulación de un plan, a los Programas Acadé- micos, a solicitud de sus Directores o del Museo, para la organización de cursos o cursillos de post-grado o de extensión.

El Museo es un servicio universitario para la conservación, presentación y estudio de los restos materiales de las sociedades prehispánicas del Perú, entendiendo como tales aquellas que se dieron antes de la llegada de los españoles a este territorio y aquellas que, aún después del siglo XVI conservaron los rasgos propios de su cultura, en forma dominante, incluidas las del área selvática.

Para dar cumplimiento a sus fines, el $\mathrm{Mu}$ seo está organizado por:

a. Una administración central (Dirección), dependiente de la Dirección Universitaria de Proyección Social;

b. Los servicios propios del Museo, que cumplen las funciones de:

1. Conservación, tratamiento y registro de los objetos (Servicio de Conservación); $\mathrm{y}$,

2. Presentación y divulgación de los mismos (Servicio de Difusión y Promoción);

c. Los Servicios de apoyo, que, a través de la actividad permanente deben permitir el enriquecimiento de los fondos del Museo, 
así como la clasificación sistemática de los materiales depositados. Ellos son:

1. El Servicio de Exploraciones y Excavaciones,

2. El Servicio de Arquitectura y Urbanismo,

3. El Servicio de Osteología y Craneometría; y,

4. El Servicio de Etnografía.

Finalmente, en relación con los servicios de apoyo, aunque no necesariamente dependientes de ellos, se desarrollan programas de investigación científica que pueden a su vez estar integrados dentro de Centros de Investigación de la Universidad o de otras Instituciones y que se adscriben al Museo a partir de un convenio. El Museo puede, por su lado, montar proyectos de investigación con financiación propia o extraña, en relación con la Dirección Universitaria de Investigaciones.

\section{A. Dirección del Museo}

La Dirección del Museo es el organismo central administrativo, técnico, que tiene la responsabilidad de las actividades del Museo. Depende de la Dirección Universitaria de Proyección Social. La Dirección del Museo está integrada por:

- El Director

- El Subdirector

- El Comité de Coordinación

- La Secretaría; y,

- El Patronato del Museo, como organismo de apoyo y consejo.

\section{Director y Subdirector}

El Director del Museo es nombrado por el Rector, a propuesta del Director Universitario de Proyección Social y, si lo considera necesario, en consulta con la Sección de Arqueología del Departamento de Ciencias Histórico-Sociales de la Universidad. Para ser Director se requiere ser arqueólogo profesional, con grado de Doctor. El Director puede ser un profesor de la Universidad.
El Director resuelve todos los asuntos relacionados con la marcha de la institución y se asesora con el Comité de Coordinación; mantiene las relaciones con las autoridades universitarias y refrenda documentos oficiales del Museo.

Cuando el Director se ausenta por un periodo menor de noventa días, lo reemplaza en sus funciones el Subdirector del Museo y, en caso de ausencia de éste, el Conservador del Museo. Cuando la ausencia del Director, por motivos de licencia, viaje de estudios u otro, es mayor a los 90 días, el Director Universitario de Proyección Social designará, por el tiempo necesario, a un Director Interino.

El Subdirector es uno de los jefes de los Servicios de apoyo que es designado para tal función, colabora con el Director en las funciones de Dirección del Museo y lo reemplaza en caso necesario.

\section{Patronato del Museo}

Este es un organismo de apoyo del Museo. Su función es la servir como medio de ayuda y consulta para el desarrollo de las actividades del Museo, así como vehículo de contacto directo con otros organismos afines del país y el extranjero. El Patronato tiene una función consultiva y al mismo tiempo asume la tarea de contribuir a la solución de los problemas económicos y de desarrollo de la institución.

El Patronato funciona en plenario y en comisiones. El Pleno del Patronato está constituido por todos sus miembros y se reúne dos veces al año: el 21 de octubre, día de la fundación del Museo, para escuchar las Memorias del Presidente del Patronato y del Director del Museo y el Discurso de Orden conmemorativo, y un día en el mes de setiembre, con el objeto de elegir al Presidente del Patronato y resolver los asuntos de su competencia.

El Patronato tiene una Comisión Permanente, constituida por el Presidente y seis miembros. El Presidente es elegido por el Pleno y los otros miembros son designados por el 
Presidente. El Director del Museo actúa como Secretario y el Conservador como Tesorero. Dicha Comisión cumple permanentemente las tareas del Patronato y está capacitado para constituir Comisiones especiales, para objetivos concretos, tales como eventos de arqueología, actividades científicas, etc., contando con todos los miembros del Patronato. La Comisión Permanente se reunirá por lo menos una vez cada dos meses.

El Patronato tiene tres clases de miembros: de Honor, de Número y Correspondientes.

La calidad de Miembros de Honor del Patronato del Museo, es un reconocimiento de la institución a las personas vivas o fallecidas, que han contribuido al desarrollo de la institución y/o al de la arqueología andina en general.

El Museo ha establecido una Galería para la memoria de tales personas, las que serán incorporadas en tal condición, en ceremonia pública. La designación de los Miembros de Honor se hará a propuesta del Comité de Coordinación, por el Pleno del Patronato.

Por constitución, el Museo reconoce como Miembros de Honor natos, al Dr. Julio C. Tello, fundador del Museo, Dr. Max Uhle, Dr. Luis E. Valcárcel, Dr. Jorge C. Muelle, Prof. Toribio Mejía Xesspe, Dr. Pedro Weiss y Sr. Rafael Larco Hoyle.

Los Miembros de Número son designados, a propuesta del Director, por el Comité de Coordinación del Museo, hasta completar el número veinticinco.

Los Miembros correspondientes son designados por el Comité de Coordinación entre los amigos y colaboradores del Museo, que se encuentran fuera de la ciudad de Lima, en el país y el extranjero. El Patronato en pleno, acordará su estructura interna y las obligaciones de sus miembros. El Pleno está constituido por todos los Miembros, con iguales derechos, pero el quórum será computado por la mitad más uno de los miembros de número.

\section{Comité de Coordinación}

El Comité de Coordinación es el organismo asesor de la Dirección y está integrado por el Director, que lo preside (o el Subdirector en su reemplazo), el Conservador, el Jefe de los Servicios de Difusión y Promoción, el Jefe de Exploraciones y Excavaciones, el jefe del Servicio de Arquitectura y Urbanismo, el Jefe del Servicio de Osteología y Craneometría y el Jefe del Servicio de Etnografía.

Además participan los Coordinadores de Catalogación y Registro, de los Servicios Generales y los Servicios de Laboratorio. En la misma condición podrán participar, a solicitud del Director, los encargados de los proyectos de investigación, cuando ello sea necesario.

El Comité de Coordinación debe reunirse por lo menos una vez al mes para conocer de la marcha del Museo, los proyectos de investigación, la solicitud de servicios del Museo, los programas de extensión, etc. Anualmente debe hacer el estudio del presupuesto del Museo para elevarlo a las autoridades competentes; igualmente, debe estudiar la forma de encauzar las donaciones, convenios con el exterior, programar y ejecutar actividades de investigación científica y de Museo, etc.

\section{Secretaría del Museo}

Es la Sección que canaliza el trámite administrativo y económico del Museo; se encarga de los archivos, actas, contabilidad de gastos, correspondencia, control de personal y almacén de útiles de escritorio.

\section{B.- Servicios del Museo}

Los Servicios del Museo son los de Conservación y Promoción y Difusión. En ellos se centraliza una de las actividades principales del Museo, la referida a la conservación, tratamiento, catalogación, registro gráfico, exposición y difusión de los objetos culturales que posee y obtiene con la ayuda de los Servicios de Apoyo. 


\section{Conservación}

Está es una de las secciones más completas y más importantes del Museo. Está bajo la responsabilidad del Conservador, que es el funcionario que sigue al Director en autoridad. Trabaja con un grupo de Coordinadores de los Servicios de Conservación y el personal a su cargo. Le toca supervigilar y garantizar el mantenimiento y limpieza del local; organizar los depósitos de objetos culturales y sus respectivos catálogos de ingreso y sistemático; mantener los servicios de fotografía, dibujo, biblioteca, etc. Y los laboratorios para el análisis y preparación de los objetos.

\section{Servicio de Mantenimiento y Vigilancia}

Está a cargo de un Coordinador del Servicio, dependiente del Conservador del Museo, se encarga de las tareas inherentes al mantenimiento del local, limpieza, vigilancia, guardianía y recepción.

\section{Limpieza y Vigilancia}

Con personal de servicio se encarga de mantener limpio el local y los objetos culturales en depósito y exposición; asimismo, en horas de atención al público, se encarga de la vigilancia de las colecciones.

\section{Recepción y guardianía}

Cuenta con un guardián y una recepcionista. El guardián cuida el local y los objetos arqueológicos, la recepcionista se encarga de la orientación a los visitantes, de las informaciones sobre el Museo, y en las horas que no hay visitantes trabaja con el Servicio de Difusión y Promoción. El guardián se encarga del almacén general de materiales de trabajo.

\section{Jardines}

Cuenta con un jardinero. Se encarga del cuidado y presentación de los jardines del Museo.

\section{Carpintería, albañilería y gasfitería}

Es un servicio de gran importancia para la conservación del local y para la preparación de las exposiciones. Debe contar con especialistas que a su vez, trabajan en el servicio de limpieza y vigilancia. Aquí debe agregarse, en lo posible, un electricista y luminotécnico.

\section{Depósitos y Catálogos}

Está bajo la dirección de un Coordinador de Catalogación y Registro. Casi se puede decir que es el núcleo de la actividad del Museo. Es en este servicio donde se centralizan todos los demás y del que se sirven quienes acuden al Museo para la investigación y el estudio: objetivo final de la institución. Por eso, la organización de los Depósitos y Catálogo requiere de personal técnico y de mucho esfuerzo.

El Museo pretende organizar sus depósitos de manera sistemática, tratando de resolver tanto el problema de la preservación de los objetos, como de su adecuado registro. En el proceso de catalogación se pretende establecer un sistema de registro con fichas perforadas para su clasificación electrónica. El registro-inventario del Museo será hecho en un libro especial, por ingreso (modificando parcialmente el ya existente). Las piezas son almacenadas tomando el criterio geográfico (región-vallesitio). Se incluye las siguientes regiones:

$$
\begin{aligned}
& \text { CN - } \text { Costa Norte.- Río Tumbes - Río } \\
& \text { Huarmey. } \\
& \text { SN }- \text { Sierra Norte Marítima.- Río La Chi- } \\
& \text { ra - Río Huarmey. } \\
& \text { CC - } \text { Costa Central - Río Pativilca - } \\
& \text { Jahuay. } \\
& \text { SC - } \text { Sierra Central Marítima. Pativilca - } \\
& \text { Río Cañete. } \\
& \text { CS - Costa Sur. - Río Chincha - Acarí. } \\
& \text { MR - Hoya del Marañón. } \\
& \text { CH - Callejón de Huaylas. } \\
& \text { AP - Hoya del Apurímac. } \\
& \text { MT - Hoya del Mantaro. } \\
& \text { UR - Hoya del Urubamba. } \\
& \text { TK - Hoya del Titicaca. } \\
& \text { ES - Valles del Extremo Sur. } \\
& \text { HU - Hoya del Huallaga. }
\end{aligned}
$$


UC - Río Ucayali.

MD - Madre de Dios

Depósitos:

1. MR-CH (Sierra Norte)

2. MT-AP-UR- (Sierra Central y Sur).

3. CC-SC (Costa Central)

4. CS-SS (Costa Sur)

5. CN-SN (Costa Norte)

6. ES-TK-HU-UC -MD (extremo Sur y Oriente).

Los valles son numerados de norte a sur, los de la costa de acuerdo a un criterio internacional ya adoptado por el Museo previamente (p.e.CC47: Costa Central-Rímac o SC47: parte alta del Rímac) y concluye con la indicación del sitio (los sitios numerados por valles). En el depósito los objetos son separados por región, por valle y por sitio y con criterio cronológico dentro de cada región; igualmente, por naturaleza y material del objeto.

En el catálogo estas divisiones se expresan con dos referencias separadas: La geográfica y la cronológica, lo que finalmente determina un cifrado corrido. (CC 7-5-FR, quiere decir Costa Central-Valle del Rímac, Sitio 5-Formativo o CS-DR: Costa Sur. Desarrollos Regionales o simplemente CS). En el espécimen va la indicación el número del registro de ingreso, precedido de las letras USM p.e. USM-001047: objeto 1047 del Museo, número del catálogo que sirva de referencia para la historia del objeto. El catálogo de ingreso general es un libro con numeración corrida que contiene las principales referencias de cada objeto y la indicación de su ficha correspondiente. Los ficheros son separados por áreas geográficas, por cronología y por materiales técnicos. Los objetos fragmentados son ingresados en otro libro, por unidades de procedencia (región, valle-sitionúmero de ingreso).

\section{Servicios Generales}

Estos son servicios dirigidos principalmente a los fines de Registro y clasificación de los materiales.

\section{El Gabinete y Archivo Fotográfico}

Es uno de los más importantes y tiene, en primer lugar, la responsabilidad de mantener el catálogo gráfico de todos los especimenes del Museo. Además, es un órgano de Difusión y Promoción y un servicio para la investigación. Igual función cumple el Gabinete de Dibujo.

\section{La Biblioteca especializada y el Archivo Central}

Son dos servicios complementarios del $\mathrm{Mu}$ seo, cuya finalidad es la información que en ellos pueda obtener cualquier investigador y el personal del Museo. Es indispensable que el Museo cuente, en su propio local, con una biblioteca de referencia para museología, tratamiento de objetos, y, finalmente, para la arqueología andina y general. El archivo centraliza toda la información del Museo, incluidos los documentos de todas las dependencias, informes, libros de campo, ficheros, catálogos, etc. Estos servicios estarán temporalmente a cargo de la Secretaría.

\section{El Servicio de Reproducciones}

Es un servicio de Difusión y Promoción, pero, al mismo tiempo, deberá cumplir la función de dotar al Museo de reproducciones de objetos originales que el Museo no puede obtener y sean considerados importantes.

Este Servicio, se encarga, igualmente, de todo lo relacionado con la elaboración de las "maquetas" de monumentos arqueológicos, cuya difusión compete al Museo. 